\title{
Mutagenic DNA Repair in Escherichia coli: Conditions for Error-free Filling of Daughter Strand Gaps
}

\author{
By JÓRUNN E. EYFJÖRD, M. H. L. GREEN AND B. A. BRIDGES \\ $M R C$ Cell Mutation Unit, University of Sussex, Falmer, Brighton BNI $9 Q G$
}

(Received 28 April 1975; revised I July 1975)

\begin{abstract}
SUMMARY
Two situations have been observed in which daughter strand gaps in DNA synthesized after exposure of excision-deficient Escherichia coli to ultraviolet light are filled but in which no mutations are formed as judged by loss of photoreversibility: (i) during the first $20 \mathrm{~min}$ of growth after u.v. irradiation, and (ii) when repair is allowed to occur in buffer. We suggest as an explanation that the majority of daughter strand gap-filling is error free and that mutations arise through a minor error-prone repair pathway which is inoperative under these conditions.
\end{abstract}

\section{INTRODUCTION}

When pyrimidine dimers induced by u.v. light in bacterial DNA pass through the replication point they give rise to gaps in the newly-synthesized DNA. These gaps are filled during subsequent incubation by a process termed post-replication repair (Rupp \& HowardFlanders, 1968). In excision-deficient strains, dimers persist indefinitely and must all be dealt with in this way. Such strains are much more sensitive to u.v. irradiation than excisionproficient strains and low doses produce far more mutants (Hill, 1965), which led to the suggestion that mutations arise during post-replication repair either during recombinational exchanges or by enzymic insertion of incorrect bases opposite dimers (Bridges, Dennis \& Munson, 1967; Witkin, 1967).

Since the recA mutation abolishes both u.v. mutagenesis and post-replication repair (Witkin, 1969; Smith \& Meun, 1970; Kondo, 1973) it seemed likely that mutations might arise as errors during recombinational daughter strand exchanges. If this were so, daughter strand gap-filling and mutation should occur concomitantly. More recently, however, evidence has accumulated that mutations occur through a minor non-recombinational component of post-replication repair (Witkin \& George, I973; Doubleday, Bridges \& Green, 1975), so that mutation formation might well show different kinetics from normal daughter strand gap-filling.

We attempted to distinguish between these alternatives in the excision-deficient strain $E$. coli WP2 $u v r A$. We measured daughter strand gap-filling by alkaline sucrose sedimentation (McGrath \& Williams, 1966) and induction of mutations by assaying reversion from Trp to $\operatorname{Trp}^{+}$. Loss of susceptibility of $\operatorname{Trp}^{+}$revertants to photoreversal was taken to indicate the occurrence of a stage in the mutational process which was irrevocable and beyond which a mutation would form whether or not the dimer was still in the DNA. 


\section{METHODS}

Bacteria. Escherichia coli WP2 uvrA (Hill, 1965), which is an excision-deficient tryptophan-requiring strain, was used.

Radiation sources. The u.v. source was a Hanovia low-pressure mercury lamp (type 12555) emitting light of predominantly $254 \mathrm{~nm}$ wavelength. A dose of $\mathrm{I} J / \mathrm{m}^{2}$ from this lamp produced approximately 30 dimers per $E$. coli genome (data of Dr A. R. Lehmann). Experiments were carried out under yellow fluorescent illumination to avoid unwanted photoreactivation.

For photoreactivation, samples were exposed $10 \mathrm{~cm}$ from two Osram 24-inch warm-light fluorescent tubes for $30 \mathrm{~min}$.

Experimental procedure. Bacteria were grown from an overnight culture to about $2 \times 10^{8} / \mathrm{ml}$ in CA medium, which consisted of $\mathrm{Mg}$ minimal medium $\left(\mathrm{Na}_{2} \mathrm{HPO}_{4}, 0.6 \%\right.$, w/v; $\mathrm{KH}_{2} \mathrm{PO}_{4}$, $0.3 \%, \mathrm{w} / \mathrm{v} ; \mathrm{NaCl}, 0.05 \%, \mathrm{w} / \mathrm{v} ; \mathrm{NH}_{4} \mathrm{Cl} 0 . \mathrm{I} \%$, w/v) supplemented with $0.4 \%$, w/v, glucose, $0.4 \%$, w/v, Casamino acids (Difco), Io $\mu \mathrm{g}$ laevo-tryptophan $/ \mathrm{ml}$ and $0.025 \%$, w $/ \mathrm{v}$, trisodium citrate). They were exposed to a low dose of u.v. light $\left(2.5 \mathrm{~J} / \mathrm{m}^{2}\right)$ and then incubated further in CA. From the time of irradiation onwards samples were taken at intervals, membranefiltered, resuspended in phage buffer (Boyle \& Symonds, 1969) and exposed to photoreactivating light for $30 \mathrm{~min}$. They were plated for mutation (reversion to $\operatorname{Tr} \mathrm{p}^{+}$prototrophy) on CA + Trp supplemented plates (Davis \& Mingioli, 1950, minimal medium $+0.4 \%$, $\mathrm{w} / \mathrm{v}$, glucose $+0.25 \%$, w/v, Casamino acids and $0.75 \mu \mathrm{g}$ laevo-tryptophan $/ \mathrm{ml}$ ). Survival was determined on the same medium. Results were not appreciably altered by the effects of photoreactivation or buffer incubation on survival, since survival was nearly $100 \%$ after $2 \cdot 5 \mathrm{~J} / \mathrm{m}^{2} \mathrm{u}$.v. irradiation.

In the experiments in Table 2 samples were also incubated for $30 \mathrm{~min}$ in buffer in the dark before being exposed to photoreactivating light. The yield of induced mutants after photoreversal was always determined as a percentage of the yield of induced mutants obtained by plating immediately after irradiation without photoreversal.

Changes in the size of newly-synthesized DNA were observed by alkaline sucrose centrifugation (McGrath \& Williams, I966, as modified by Green et al. 1973). Samples were pulselabelled for 4 or $8 \mathrm{~min}$ in $\mathrm{CA}$ medium supplemented with $50 \mu \mathrm{Ci}\left[{ }^{3} \mathrm{H}\right]$ thymidine $/ \mathrm{ml}$ (20 to $25 \mathrm{Ci} / \mathrm{mmol}$ ) and $100 \mu \mathrm{g}$ deoxyadenosine $/ \mathrm{ml}$. Five or $10 \mathrm{~min}$ pulses were used in irradiated samples to help compensate for the inhibition of DNA synthesis by u.v. irradiation (Bridges \& Sedgwick, 1974). To follow the filling of daughter strand gaps the bacteria were membranefiltered after the pulse, washed with buffer, resuspended in fresh growth medium or buffer, and incubated further. At intervals, samples of 50 to $80 \mu \mathrm{l}$, containing less than $10^{7}$ cells, were layered in $0.1 \mathrm{ml}$ Sarkosyl, on the surface of $5 \mathrm{ml}(5$ to $20 \%)$ alkaline sucrose gradients (Green et al. 1973 ). Gradients were spun $90 \mathrm{~min}$ at $32000 \mathrm{rev} / \mathrm{min}$ in a Beckman $\mathrm{SW}_{50 . \mathrm{I}}$ rotor (Green et al. 1973).

\section{RESULTS}

When $E$. coli WP2 $u v r A$ was incubated in CA medium immediately after exposure to u.v. light, the extent of photoreversal (approximately 80 to $90 \%$ ) was the same (or greater) 20 min after irradiation as immediately after it. This was observed in seven independent experiments in which loss of photoreversibility was followed over varying lengths of time (Table I) and suggests that mutations to Trp ${ }^{+}$were not formed during this period. This delay of 20 min or more was most evident when photoreversal was carried out in buffer. Photoreversibility tends to be lost more rapidly if the actual photoreversal is carried out in 


\section{Table I. Photoreversibility following incubation in Casamino acids medium for different times after irradiation}

Samples were incubated in CA medium after u.v. irradiation, transferred to buffer and exposed to photo. reversing light at times o to $60 \mathrm{~min}$.

\begin{tabular}{crrrrr}
\multicolumn{5}{c}{$\begin{array}{c}\text { Induced mutants remaining after photoreversal }(\%)^{*} \\
\text { Time in CA medium before photoreversal } \\
\text { (min): }\end{array}$} \\
$\begin{array}{c}\text { Experiment } \\
\text { no. }\end{array}$ & \multicolumn{1}{c}{$\begin{array}{c}\text { O } \\
\text { I }\end{array}$} & 30 & 40 & 60 \\
I & 13.6 & 13.4 & & & \\
2 & 12.3 & 10.6 & & & \\
3 & 8.7 & 8.6 & & & \\
4 & 7.9 & 7.6 & 9.3 & & \\
5 & 17.3 & 9.0 & 17.8 & 27.5 & 35.0 \\
6 & 7.0 & 5.8 & 6.6 & & 41.0 \\
7 & 18.8 & 14.3 & 21.2 & 21.8 & 34.8
\end{tabular}

* Given as a percentage of the total mutant yield obtained by plating immediately after irradiation without photoreversal.
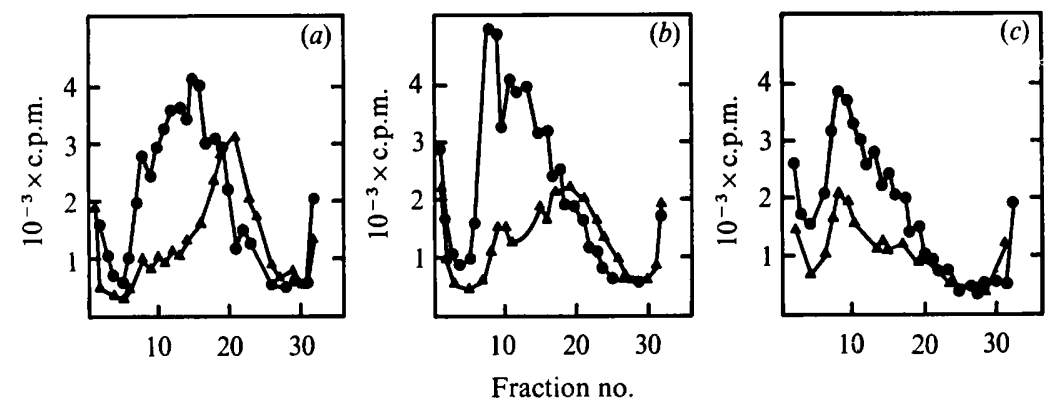

Fig. I. Alkaline sucrose sedimentation profiles of newly-synthesized DNA from E. coli WP2 uvrA. Sedimentation from right to left. (a) $\bullet$, No u.v., $4 \mathrm{~min}$ in $\left[{ }^{3} \mathrm{H}\right]$ thymidine; $\Delta, 2.5 \mathrm{~J} / \mathrm{m}^{2}$ u.v., $5 \mathrm{~min}$ in $\left[{ }^{3} \mathrm{H}\right]$ thymidine. (b) $\bullet$, No u.v., $4 \mathrm{~min}$ in $\left[{ }^{3} \mathrm{H}\right]$ thymidine followed by $5 \mathrm{~min}$ in non-radioactive medium; $\Delta, 2 \cdot 5 \mathrm{~J} / \mathrm{m}^{2}$ u.v., $5 \mathrm{~min}$ in $\left[{ }^{3} \mathrm{H}\right]$ thymidine, $5 \mathrm{~min}$ in non-radioactive medium. (c) $\bullet$, No u.v., $4 \mathrm{~min}$ in $\left[{ }^{3} \mathrm{H}\right]$ thymidine, $15 \mathrm{~min}$ in non-radioactive medium; $\Delta, 2.5 \mathrm{~J} / \mathrm{m}^{2}$ u.v., $5 \mathrm{~min}$ in $\left[{ }^{3} \mathrm{H}\right]-$ thymidine, $15 \mathrm{~min}$ in non-radioactive medium.

growth medium (Doubleday et al. 1975), presumably because some of the gaps already in existence at the beginning of light exposure can still be filled in growth medium in an errorprone manner, whereas in buffer, as is shown here, gap filling is essentially error-free.

Efficiency of photoreversibility tends to vary slightly from day to day, and in a given experiment the value obtained may be greatly affected by the number of mutants per plate in the unirradiated control. However, neither factor affects comparisons within a single experiment.

Alkaline sucrose sedimentation was used to determine the reduction in size of the DNA synthesized after exposure to u.v. light and to follow its return to normal on subsequent incubation. The fluence used here $\left(2 \cdot 5 \mathrm{~J} / \mathrm{m}^{2}\right)$ reduced the rate of DNA synthesis by about $25 \%$. Figure $\mathrm{I}(a)$ shows that the DNA synthesized immediately after exposure to u.v. light was of low molecular weight (i.e. contained additional gaps). It can be seen that most of the gaps formed in the first $5 \mathrm{~min}$ after irradiation were filled within $15 \mathrm{~min}$ (Fig. I $a, c$ ). DNA synthesized on an unirradiated template during a 4 min pulse was also of reduced molecular 


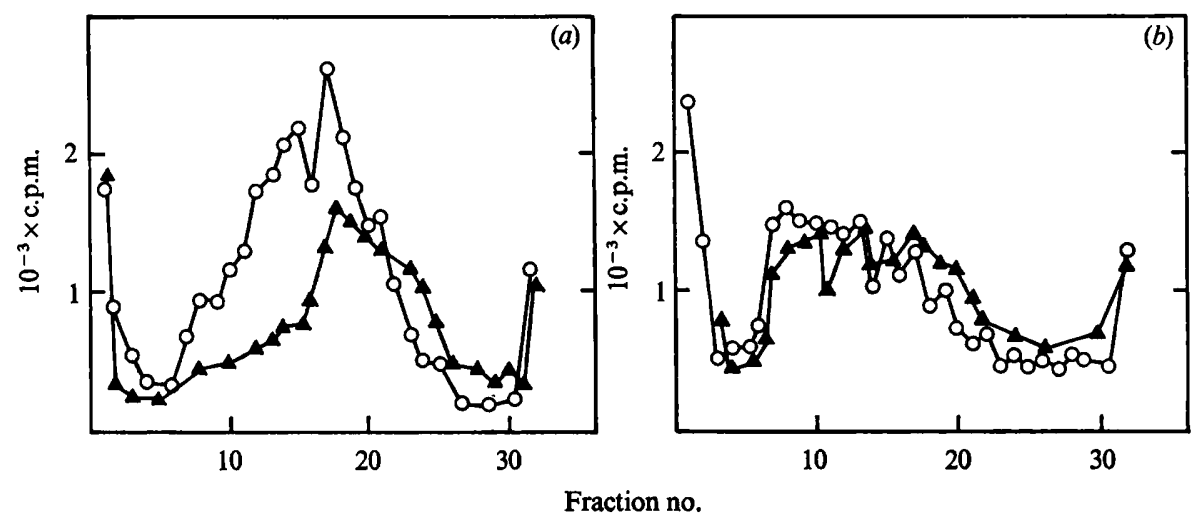

Fig. 2. Alkaline sucrose sedimentation profiles of newly-synthesized DNA in WP2 $u v r A$. Sedimentation from right to left. (a) $\bigcirc$, no u.v., incubated $30 \mathrm{~min}$ in CA medium, labelled for $8 \mathrm{~min}$ in $\left[{ }^{3} \mathrm{H}\right]-$ thymidine; $\boldsymbol{\Delta}, 2.5 \mathrm{~J} / \mathrm{m}^{2}$ u.v., $30 \mathrm{~min}$ in $\mathrm{CA}$ medium, labelled $10 \mathrm{~min}$ in $\left[{ }^{3} \mathrm{H}\right]$ thymidine. $(b) \mathrm{O}$, No u.v., $30 \mathrm{~min}$ in CA medium, $8 \mathrm{~min}$ in $\left[{ }^{3} \mathrm{H}\right]$ thymidine, then incubated in buffer for $30 \mathrm{~min} ; \boldsymbol{\Delta}$, $2.5 \mathrm{~J} / \mathrm{m}^{2}$ u.v., $30 \mathrm{~min}$ in CA medium, $10 \mathrm{~min}$ in $\left[{ }^{3} \mathrm{H}\right]$ thymidine, then incubated $30 \mathrm{~min}$ in buffer.

Table 2. Photoreversibility before and after incubation in buffer

\begin{tabular}{|c|c|c|c|c|}
\hline \multirow{2}{*}{$\begin{array}{c}\text { Experiment } \\
\text { no. }\end{array}$} & \multirow{2}{*}{$\begin{array}{l}\text { Initial incubation } \\
\text { period in CA medium } \\
\text { (min) }\end{array}$} & \multicolumn{3}{|c|}{$\begin{array}{c}\text { Induced mutants remaining } \\
\text { after } 30 \mathrm{~min} \\
\text { photoreversal* }(\%)\end{array}$} \\
\hline & & (A) & (B) & (C) \\
\hline I & 20 & 10.6 & 10.2 & \\
\hline 2 & 30 & $9 \cdot 3$ & $7 \cdot 2$ & $24 \cdot 8$ \\
\hline 3 & & 6.6 & 3.7 & $4 \mathrm{I} \cdot 0$ \\
\hline 4 & 40 & $27 \cdot 5$ & $20 \cdot 6$ & $35^{\circ} \circ$ \\
\hline 5 & & $2 \mathrm{I} \cdot 8$ & 14.3 & $34 \cdot 8$ \\
\hline
\end{tabular}

* Induced mutants remaining after photoreversal are given as a fraction of the total mutant yield obtained by plating immediately after irradiation without photoreversal. (A) Samples u.v. irradiated, incubated in CA medium for the time indicated, transferred to buffer and immediately photoreversed. (B) Samples u.v. irradiated, incubated in CA medium for the time indicated, transferred to buffer, incubated for 30 min in the dark and then photoreversed. (C) Samples u.v. irradiated, incubated in CA medium for time indicated and incubation continued for a further $30 \mathrm{~min}$ in CA medium before transfer to buffer and photoreversal (Expts 4 and $5,20 \mathrm{~min})$.

weight. (Bridges \& Sedgwick, 1974; Lehmann \& Ormerod, 1969). However, the unirradiated sample reached high molecular weight after $5 \mathrm{~min}$ incubation, at which stage there was only a slight increase in the molecular weight of the irradiated sample (Fig. Ib). After Io min additional incubation the irradiated sample also reached a high molecular weight (Fig. Ic). The apparent loss of counts in Fig. I $(b)$ and $(c)$ compared with Fig. I $(a)$ was mainly due to losses at the additional filtration step rather than to DNA breakdown. Similar results were consistently obtained in a large number of experiments of this type. It would therefore appear that at a time when daughter strand gaps were being filled, no mutations were being formed.

Another situation where gap-filling can be demonstrated without apparent mutation formation is in phosphate buffer. After incubation beyond 20 to $30 \mathrm{~min}$ in CA medium, photoreversibility began to decline. At this stage samples were transferred to phosphate buffer and incubated for $30 \mathrm{~min}$ in the dark before photoreversal. Photoreversibility of mutations did not decline during the incubation in buffer (Table 2), showing that no addi- 
tional mutations were formed at this time. Nevertheless gap-filling was regularly found to occur during buffer incubation (Fig. 2) in agreement with earlier work (Bridges \& Sedgwick, 1974). This gap-filling in buffer must therefore presumably have been error-free.

\section{DISCUSSION}

The present results reveal a discrepancy between mutation induction and filling of daughter strand gaps in that there are two apparent situations where daughter strand gaps are filled and where photoreversibility of u.v.-induced mutations is not lost, namely during the first 20 min of growth and when gaps formed in growth medium are filled in phosphate buffer. 'How valid is this conclusion? From Fig. I and from I 4 similar gradient experiments it can be determined that in this strain and under these conditions, it takes about Io min to fill a daughter strand gap associated with u.v. damage. In Fig. I (b), for instance, the longest period available for gap filling was $10 \mathrm{~min}$, and only a small amount had occurred. In Fig. I $(c)$ the shortest time available for gap filling was $15 \mathrm{~min}$ and gap filling was virtually complete.

It should be noted that gap-filling is considerably more rapid in this strain than in most KI2 strains. If we take a conservative average figure of 12 min for gap-filling, DNA synthesized during the first $8 \mathrm{~min}$ after irradiation will be repaired within the first $20 \mathrm{~min}$. In experiments under these conditions at least $90 \%$ of the induced mutants lost photoreversibility within 90 min of u.v. irradiation (about $\mathrm{I} \cdot 5$ generations, allowing for inhibition of DNA synthesis) (Doubleday et al. 1975; J. Eyfjörd, unpublished observations). If the gap-filling occurring in the first 20 min led to mutation, one would expect at least $8 \%$ of induced mutants to lose photoreversibility within $20 \mathrm{~min}$. This would lead to an increase of $\mathrm{I} \cdot 5-$ to 2 -fold in the fraction of mutants remaining after photoreversal, whereas in fact no increase occurred (Table I). A similar calculation would predict that at least $18 \%$ of induced mutants should lose photoreversibility within $30 \mathrm{~min}$, yet the actual values obtained in four experiments were between 0 and $2.5 \%$ (Table I).

It must be stressed that our calculations are conservative, and that an increase of $\mathrm{I} \cdot 5$-fold or more in the number of mutants remaining after photoreversal would certainly have been detected. It would therefore appear that mutations were not formed by gap-filling during the first 20 to 30 min after u.v. irradiation. Such a conclusion is dependent on the assumption that the photoreversibility of pyrimidine dimers did not increase with time. There is no evidence of any such increase during incubation of this strain after u.v. irradiation (Setlow, 1967).

It could be argued that mutations arise only in a small fraction of cells and that these do not replicate their DNA during the first 20 min of growth. Such an objection would not, however, apply to the buffer situation, since mutations have already begun to lose photoreversibility during the preceding period of post-irradiation growth. Nor would it apply to the effect of chloramphenicol, which has been shown to have a similar effect to buffer in halting loss of photoreversibility without halting gap-filling (S. G. Sedgwick, personal communication). There exists a precedent for the filling of daughter strand gaps without mutation induction in a uvrA exrA strain (Bridges \& Sedgwick, 1974) which does not form $\mathrm{Tr}^{+}$mutants after u.v. irradiation.

We suggest as an explanation of our results the hypothesis that most daughter strand gapfilling in $E$. coli occurs by an error-free process, probably involving recombinational exchanges (Rupp et al. 1971) and that mutations arise as errors during the operation of a minor non-recombinational process which contributes little to the overall filling of gaps following 
low u.v. doses. It is this process which we postulate to be inoperative during the first 20 to 30 min of post-irradiation growth and in phosphate buffer.

Whether gaps which would have been repaired in an error-prone manner in rich medium are filled in an error-free manner in buffer, or whether they remain unfilled, cannot be stated. Certainly a small fraction of gaps remaining unfilled would be very difficult to identify. The persistence of full photoreversibility for at least $20 \mathrm{~min}$ after u.v. irradiation could indicate that error-prone gap-filling takes considerably longer than the predominant error-free gapfilling process. An alternative explanation could be that the error-prone repair process is not constitutive (Defais et al. 197I; Witkin \& George, 1973), and that it takes about 20 min to become induced.

The present results are in no way inconsistent with the hypothesis that daughter strand gaps may lead to mutations but they show that there exist situations where gap-filling is essentially non-mutagenic. More specifically, it can be concluded that error-prone repair of daughter strand gaps is turned off in buffer. The results tend to corroborate other evidence (Doubleday et al. 1975; Witkin \& George, 1973; Radman, 1974; Devoret, 1974) that errorprone post-replication repair may be a distinct minor pathway.

J.E.E. acknowledges receipt of a scholarship from the Icelandic Science Foundation.

\section{REFERENCES}

BOYLE, J. M. \& SYMONDS, N. (1969). Radiation-sensitive mutants of T4D. I. T4Y; a new radiation-sensitive mutant; effect of the mutation on radiation survival, growth and recombination. Mutation Research 8 , $43 \mathrm{I}-439$.

Bridges, B. A., Dennis, R. E. \& Munson, R. J. (1967). Differential induction and repair of ultraviolet damage leading to true reversions and external suppressor mutations of an ochre codon in Escherichia coli $\mathrm{B} / \mathrm{r}$ WP2. Genetics $\mathbf{5 7}, 897-908$.

Bridges, B. A. \& Sedgwick, S. G. (1974). Effect of photoreactivation on the filling of gaps in deoxyribonucleic acid synthesized after exposure of Escherichia coli to ultraviolet light. Journal of Bacteriology II7, 1077-1081.

Davis, B. D. \& Mingroli, E. S. (1950). Mutants of Escherichia coli requiring methionine or vitamin BI2. Journal of Bacteriology 60, 17-28.

Defais, M., Fauquet, P., Radman, M. \& Errera, M. (I97I). Ultraviolet reactivation and ultraviolet mutagenesis of $\lambda$ in different genetic systems. Virology 43, 495-503.

Devoret, R. (1974). Mechanisms involved in the recovery of phage $\lambda$ from UV damage. In Molecular Mechanisms for the repair of DNA. Edited by P. C. Hanawalt and R. B. Setlow. New York: Plenum Press.

Doubleday, O. P., Bridges, B. A. \& Green, M. H. L. (1975). Mutagenic DNA repair in Escherichia coli. II. Factors affecting loss of photoreversibility of UV-induced mutations. Molecular and General Genetics (in the Press).

Green, M. H. L., Gray, W. J. H., Sedgwick, S. G. \& Bridges, B. A. (I973). Repair of DNA damage produced by gamma-radiation in Escherichia coli $\mathrm{K}-\mathrm{I} 2$ and a radiation-sensitive $\operatorname{exr} A$ derivative during inhibition of protein synthesis and normal DNA replication by chloramphenicol. Journal of General Microbiology 77, 99-108.

Hill, R. F. (1965). Ultraviolet-induced lethality and reversion to prototrophy in Escherichia coli strains with normal and reduced dark repair ability. Photochemistry and Photobiology 4, 563-568.

KonDO, S. (1973). Evidence that mutations are induced by errors in repair and replication. Genetics $\mathbf{7 3}$, I09-122.

Lehmann, A. R. \& Ormerod, M. G. (1969). Artefact in the measurement of the molecular weight of pulselabelled DNA. Nature, London 221, 1053-I056.

McGrath, R. \& Williams, R. (I966). Reconstruction in vivo of irradiated Escherichia coli deoxyribonucleic acid; the rejoining of broken pieces. Nature, London 212, 534-535.

RADMAN, M. (1974). SOS repair: an inducible mutagenic DNA repair. In Molecular Mechanisms for the repair of DNA. Edited by P. C. Hanawalt and R. B. Setlow. New York: Plenum Press.

Rupp, W. D. \& Howard-Flanders, P. (1968). Discontinuities in the DNA synthesized in an excisiondefective strain of Escherichia coli following ultraviolet irradiation. Journal of Molecular Biology 3r, 29I-304. 
Rupp, W. D., Wilde, C. E. III, Reno, D. L. \& Howard-Flanders, P. (I97I). Exchanges between DNA strands in ultraviolet-irradiated Escherichia coli. Journal of Molecular Biology 6r, 25-44.

SETLOW, R. B. (1967). Steps in the repair of DNA: fact and fancy. Brookhaven Symposia in Biology 20, I-I 6.

SmITH, K. C. \& Meun, D. H. C. (1970). Repair of radiation-induced damage in Escherichia coli. I. Effect of mutations on post-replication repair of damage due to ultraviolet radiation. Journal of Molecular Biology 51, 459-472.

WITKIN, E. M. (1967). Mutation-proof and mutation-prone modes of survival in derivatives of Escherichia coli в differing in sensitivity to ultraviolet light. Brookhaven Symposia in Biology 20, 17-55.

WITKIN, E. M. (1969). The mutability toward ultraviolet light of recombination-deficient strains of Escherichia coli. Mutation Research 8, 9-14.

Witkin, E. M. \& George, D. L. (I973). Ultraviolet mutagenesis in polA and uvr $A$ polA derivatives of Escherichia coli $\mathrm{B} / \mathrm{r}$ : evidence for an inducible error-prone repair system. Genetics $73, \mathrm{s9} \mathrm{I}-\mathrm{I} 08$. 